\title{
Secondary metabolites of six Siberian and Crimean Armillaria species and their in vitro phytotoxicity to pine, larch and poplar
}

\author{
Tatyana V Antipova (1), \\ Valentina P Zhelifonova ${ }^{(1)}$, \\ Yulia A Litovka ${ }^{(2-3)}$, \\ Igor N Pavlov ${ }^{(2-3)}$, \\ Boris P Baskunov (1), \\ Zhanna A Kokh ${ }^{(2-4)}$, \\ Polina V Makolova ${ }^{(2-3)}$, \\ Anton A Timofeev ${ }^{(2)}$, \\ Anatoly G Kozlovsky ${ }^{(1)}$
}

(1) GK Skryabin Institute of Biochemistry and Physiology of Microorganisms, FRC Pushchino Centre for Biological Research, Russian Academy of Sciences, 5 Prosp. Nauki, Pushchino, Moscow Region, 142290 (Russia); (2) VN Sukachev Institute of Forest, FRC KSC, Siberian Branch, Russian Academy of Sciences, 50 Akademgorodok Str., Bld 28, Krasnoyarsk, 660036 (Russia); (3) FSBEIHE MF Reshetnev Siberian State University of Science and Technology, 82 Prosp. Mira, Krasnoyarsk, 660037 (Russia); (4) FSBEIHE Krasnoyarsk State Agrarian University, 90 Prosp. Mira, Krasnoyarsk, 660049 (Russia)

@ Tatyana V Antipova (tatantip@rambler.ru)

Received: Apr 06, 2021 - Accepted: Dec 02, 2021

Citation: Antipova TV, Zhelifonova VP, Litovka YA, Pavlov IN, Baskunov BP, Kokh ZA, Makolova PV, Timofeev AA, Kozlovsky AG (2022). Secondary metabolites of six Siberian and Crimean Armillaria species and their in vitro phytotoxicity to pine, larch and poplar. iForest 15: 38-46. - doi: 10.3832/ifor3840014 [online 2022-02-04]

Communicated by: Alberto Santini
Basidiomycetes Armillaria infect deciduous, coniferous and fruit trees, causing enormous economic damage. The role of secondary metabolites (tricyclic sesquiterpene aryl esters - melleolides) in the life cycle and pathogenesis of Armillaria is under active investigation. To date, not all species of Armillaria have been tested for the biosynthesis of melleolides. We investigated the secondary metabolite profiles of six root-pathogenic species of the genus Armillaria (A. borealis Marxmüller \& Korhonen, A. cepistipes Velenovský, A. gallica Marxm, A. mellea (Vahl) P. Kummer, A. sinapina Bérubé \& Dessur, A. ostoyae (Romagn.) Herink) distributed in Siberia (South Krasnoyarsk Krai, Republic of Tyva, Republic of Khakassia, Taimyr Peninsula), Russian Far East (Sikhote-Alin) and Crimea (Krymsky National Park, Chatyr-Dag Mountain Lower Plateau). A total of 15 compounds were identified in the metabolome profile. Two compounds (melleolide $\mathrm{D}$ and melledonal $\mathrm{C}$ ) are synthesized by all investigated strains irrespective of their geographic location and host plant. The maximum spectrum of melleolides (7-8 compounds) was found in isolates of $A$. borealis, A. gallica, $A$. sinapina, $A$. ostoyae. In submerged culture, the maximum accumulation of melleolides varied from 2 up to $239 \mathrm{mg} \mathrm{l}^{-1}$. A mixture of melleolide $D$ and melledonal $C(1: 1)$ synthesized by the most productive strain $A$. mellea Cr2-17 was first found to have a phytotoxic action on the growth parameters of the callus culture Populus balsamifera and 10-day-old conifer seedlings. A $0.5 \%$ concentration of melleolides caused a credible decrease of $P$. balsamifera callus raw biomass; a decrease of the viability of Larix sibirica and, which is especially significant, Pinus sylvestris seedlings; inhibition of stem and root growth processes; dechromation of foliage; loss of turgor. The occurrence of a broad range of melleolides in the metabolome profile and two common compounds in all investigated strains, with a phytotoxic action at their sufficiently high concentration, enables considering the synthesis of melleolides by Armillaria fungi as one of the possible mechanisms of their pathogenicity efficiently realized in strains characterized by overproduction of melleolides under natural conditions.

Keywords: Melleolides, Metabolome, Armillaria fungi, Phytotoxicity, Callus, Coniferous Plants

\section{Introduction}

Armillaria is one of the most important genera of fungal root pathogens worldwide. It attacks hundreds of tree species in both timber (e.g., Abies, Picea, Pinus, Pseudotsuga) and agronomic (e.g., Citrus, Juglans, Malus, Prunus, Vitis) systems in both hemispheres and in a range of climates (Baumgartner et al. 2011). Most species have a saprophytic lifestyle during which they contribute to the decomposition of organic material in forest ecosystems, and they become pathogens when environmental conditions are favorable for infection (Coetzee et al. 2018). Armillaria colonize living roots, causing necrotic changes in plant tissue, and then use dead tissue as a source of nutrition (Baumgartner et al. 2011). After the death of a plant, the fungi are preserved as saprophytes on infected parts of the root system and can inoculate other plants. The genus Armillaria includes more than 40 species, which differ significantly by their virulence. They include agents of forest stands' mass dying such as A. ostoyae (Romagn.) Herink, A. mellea (Vahl) P. Kumm., A. sinapina Bérubé \& Dessur.) and weak pathogens developing on severely weakened trees A. gallica Marxm., as well as predominantly saprotrophs that colonize dead wood (A. cepistipes Velen - Prospero et al. 2004, Marçais \& Bréda 2006). Most Armillaria species feature the formation of a mycelium fan under the bark of severely weakened and drying trees, frequently on weakened trees (Fig. 1). At the first symptoms of a lesion (dechromation of foliage, exudation of pitch), a sufficiently rapid death of the tree is to be expected (Pavlov et al. 2017). Within the species, the virulence of particular isolates varies (Morrison \& Pellow 2002). The most virulent species, e.g., A. ostoyae, occur more often on woody plants than on agronomic cultures (Baumgartner et al. 2011). Armillaria fungi are widespread throughout the world; some species are distributed transcontinentally, while others are re- 


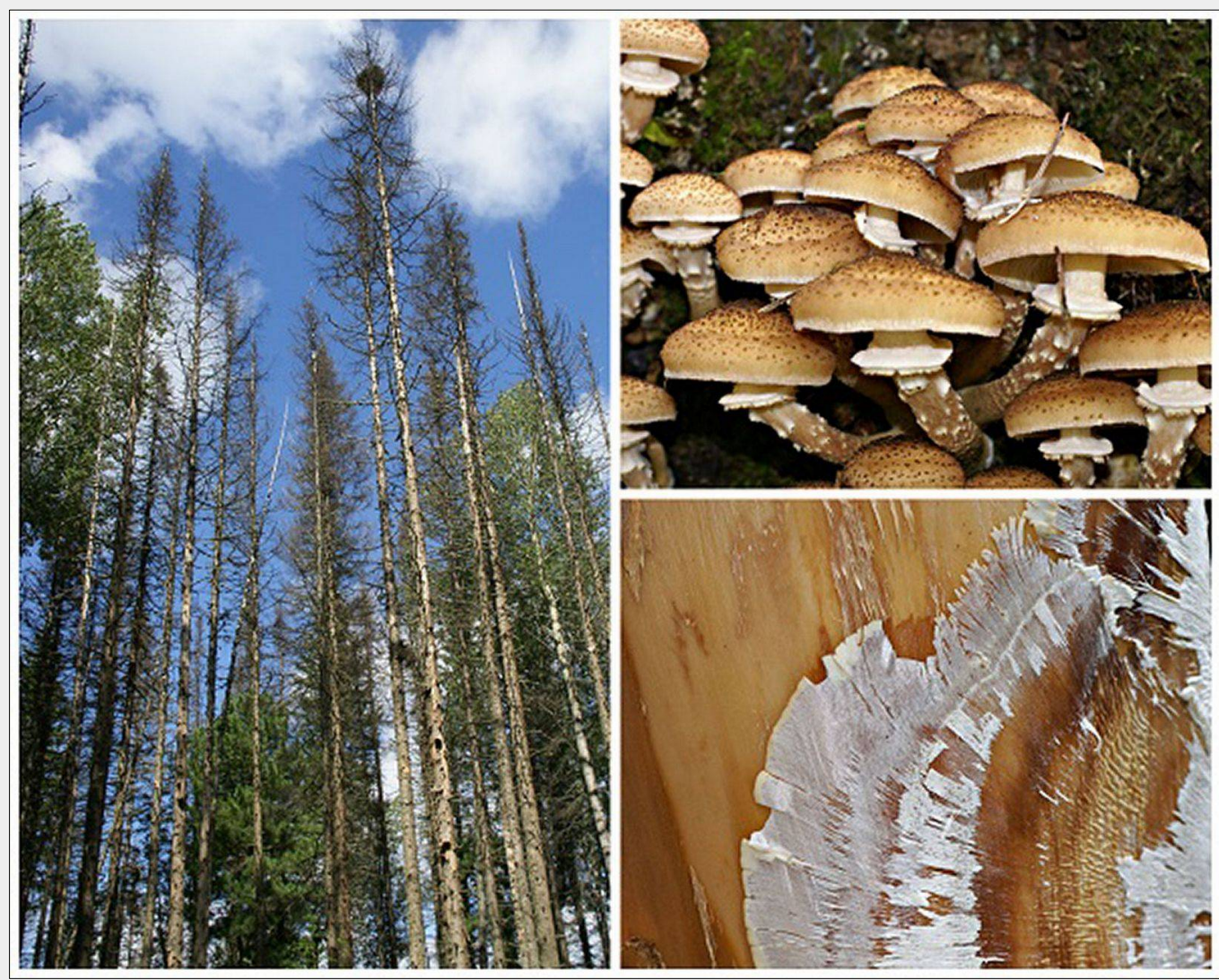

Fig. 1 - Decline of forest stands under the action of Armillaria root pathogens (left). (Upper right): basidiomes; (lower right): mycelium fan under the bark of Abies sibirica.

stricted to particular regional areas. The combination between geography, host plant species and host population structure and diversity explains Armillaria distribution (Guillaumin et al. 1993).

Research into the physiology of Armillaria root pathogens is associated primarily with the characterization of wood-degrading enzymes and the biosynthesis of secondary metabolites. For a phytopathogen to penetrate to the root system, it evidently requires a set of wood-degrading enzymes efficiently decomposing wood lignocellulose components (Baumgartner et al. 2011). The enzymes enable the fungi to penetrate into the bark of the root and then to decompose the main cambium and secondary xylem. The role of secondary metabolites in the life cycle and pathogenesis of Armillaria is also under active investigation. The main group of the secondary metabolites of these fungi are sesquiterpene aryl esters (melleolides). To date, over 70 structures of melleolides, which belong to one of the largest classes of natural compounds, are known: they are a hybrid molecule consisting of two structural elements of different biosynthetic origin (Dorfer et al. 2019a) The first element consists of the $C_{15}$ tricyclic core, which is formed from the universal precursor of sesquiterpenes, geranyldiphosphate. The second part of the melleolide molecule contains orsellinic acid, which is a phenol derivative of polyketide origin. Fungi of the genus Armillaria possess a unique capability of binding these two building blocks by esterification. Further hydroxylation at various positions of sesquiterpene, oxidation of primary alcohol at C-1 to the aldehyde or carboxyl groups, shift or reduction of the secondary bond of cyclohexene, formation of methyl ester at $0-5^{\prime}$ and chlorination at C-6' of the orsellinic ring lead to the formation of various structural variants of the molecule (Misiek \& Hoffmeister 2012, Dorfer et al. 2019b).

Depending on their structures, melleolides manifest various biological activities. Several compounds found in A. mellea, including armillarikin, armillaridin, arnamiol possess a potential anti-tumour cytotoxic action (Chen et al. 2016). For many melleolides, an antimicrobial activity and antioxidant properties have been shown (Momose et al. 2000, Misiek \& Hoffmeister 2012). An antifungal activity is characteristic of melleolides harbouring a $\Delta^{2,4}$ double bond in the protoilludene ring, but for melleolides with a $\Delta^{2,3}$ double bond it has not been shown (Bohnert et al. 2014). Investigation of the phytotoxigenic activity of melleolides has been limited to the callus culture Picea abies (Peipp \& Sonnenbichler 1992) and salad leaves (Kobori et al. 2015).

In cultivation of Armillaria fungi, melleolides are found in the mycelium and culture liquid. The spectrum of melleolides in an isolate does not, as a rule, exceed 10 compounds. To date, not all species of Armillaria have been tested for the biosynthesis of melleolides. Production of melleolides has been shown in 10 North American species; in European and Asian isolates of the species A. mellea, A. gallica, A. cepistipes and A. ostoyae; in European and
North American isolates of A. tabescens (= Desarmillaria tabescens) and New Zealand strain A. novae-zelandiae (Dorfer et al. 2019b). The ability to synthesize melleolides and their relation to phytopathogenicity has been found in Siberian and Far Eastern strains A. borealis Marxm. \& Korhonen, A. cepistipes, A. gallica, A. ostoyae and A. sinapina (Zhelifonova et al. 2019). The aim of this work was to investigate the secondary metabolite spectrum of Armillaria fungi isolated in Siberia and Crimea and their in vitro phytotoxicity on seedlings of Pinus sylvestris $L$. and Larix sibirica $L$. and callus culture of the Populus alba.

\section{Methods}

\section{Isolation of fungi}

We studied 17 fungal strains of the genus Armillaria. The strains were isolated in 2009-2018 in Siberia (Taimyr Peninsula, South Krasnoyarsk Krai, Republic of Tyva, Republic of Khakassia), Russian Far East (Sikhote-Alin) and Crimea (Krymsky National Park, Chatyr-Dag Mountain Lower Plateau) from coniferous (Abies sibirica Ledeb., Picea jezoensis (Siebold \& Zucc.) Carrière) and broadleaved plants (Alnus Mill, Betula pendula Roth, Carpinus betulus L., Pyrus L., Quercus petraea (Matt.) Liebl., B. tortuosa Ledeb.) (Tab. 1, Fig. 2). The strains were isolated to pure culture from basidiospores, basidiomes, rhizomorphs and wood onto $2 \%$ malt extract agar with 0.5\% tannin (MEA+T - Maloy 1974, Whitney et al. 1978, Bukhalo 1988). The cultures were stored on MEA slants (Difco, USA) at 
Tab. 1 - Location / source of isolation of the Armillaria fungal complex. (AccNo): NCBI GenBank accession numbers of all nucleotide sequences of gene regions ITS (https://www.ncbi.nlm.nih.gov/nuccore/). Authors: (1) Kolesnikova Al, Pavlov IN, Litovka YA, Oreshkova NV, Timofeev AA, Litvinova EA, Petrenko SM, Krutovsky KV; (2) Litovka YA, Pavlov IN; (3) Pavlov IN, Litovka YA.

\begin{tabular}{|c|c|c|c|c|c|c|c|}
\hline Species & Strain & Source & Host plant & Coordinates & $\begin{array}{l}\text { Sampling } \\
\text { year }\end{array}$ & Authors & AccNo \\
\hline \multirow[t]{4}{*}{ A. borealis } & 435 & Basidiospores & Abies sibirica & $\begin{array}{l}54.688817 \mathrm{~N} \\
93.193017 \mathrm{E}\end{array}$ & 2009 & (1) & MW418551 \\
\hline & Kh3s-17 & Basidiospores & Betula pendula & $\begin{array}{l}54.628268 \mathrm{~N} \\
88.633428 \mathrm{E}\end{array}$ & 2017 & $(2)$ & OK239656 \\
\hline & Kr2-17 & Wood & Abies sibirica & $\begin{array}{l}55.914859 \mathrm{~N} \\
92.724886 \mathrm{E}\end{array}$ & 2017 & (3) & OK254155 \\
\hline & Kh2w-17 & Wood & Betula pendula & $\begin{array}{l}54.644965 \mathrm{~N} \\
88.723071 \mathrm{E}\end{array}$ & 2017 & $(2)$ & OK271419 \\
\hline \multirow[t]{5}{*}{ A. cepistipes } & Kh5s-17 & Basidiospores & Betula pendula & $\begin{array}{l}54.404991 \mathrm{~N} \\
89.995636 \mathrm{E}\end{array}$ & 2017 & (3) & OK287087 \\
\hline & Kh6w-17 & Wood & Betula pendula & $\begin{array}{l}55.298777 \mathrm{~N} \\
88.787225 \mathrm{E}\end{array}$ & 2017 & $(2)$ & OK324335 \\
\hline & Kh7s-17 & Basidiospores & Betula pendula & $\begin{array}{l}55.315083 \mathrm{~N} \\
88.809285 \mathrm{E}\end{array}$ & 2017 & (3) & OK324330 \\
\hline & Kr1-15 & Basidiome & Betula pendula & $\begin{array}{l}56.180884 \mathrm{~N} \\
92.182450 \mathrm{E}\end{array}$ & 2015 & (3) & OK324327 \\
\hline & Kr4tr-15 & Wood & Abies sibirica & $\begin{array}{l}56.173182 \mathrm{~N} \\
92.180247 \mathrm{E}\end{array}$ & 2015 & $(2)$ & OK324329 \\
\hline \multirow[t]{2}{*}{ A.gallica } & Cr7-17 & Rhizomorphs & Carpinus betulus & $\begin{array}{l}44.775218 \mathrm{~N} \\
34.278550 \mathrm{E}\end{array}$ & 2017 & (3) & OK324333 \\
\hline & $\mathrm{Cr} 3-17$ & Rhizomorphs & Quercus petraea & $\begin{array}{l}44.672970 \mathrm{~N} \\
34.170293 \mathrm{E}\end{array}$ & 2017 & (3) & OK287074 \\
\hline \multirow[t]{2}{*}{ A.mellea } & Cr1-17 & Basidiome & Pyrus L. & $\begin{array}{l}44.665507 \mathrm{~N} \\
34.270732 \mathrm{E}\end{array}$ & 2017 & (3) & OK324325 \\
\hline & $\mathrm{Cr} 2-17$ & Basidiome & Pyrus L. & $\begin{array}{l}44.665507 \mathrm{~N} \\
34.270734 \mathrm{E}\end{array}$ & 2017 & $(2)$ & OK324331 \\
\hline A. ostoyae & FE $21 w-2011$ & Wood & Picea jezoensis & $\begin{array}{r}44.635680 \mathrm{~N} \\
135.174003 \mathrm{E}\end{array}$ & 2011 & (3) & OK324328 \\
\hline \multirow[t]{3}{*}{ A. sinapina } & Tm1-2018 & Basidiome & Betula tortuosa & $\begin{array}{l}69.529492 \mathrm{~N} \\
88.372237 \mathrm{E}\end{array}$ & 2018 & $(2)$ & OK324326 \\
\hline & Kr7tr-16 & Wood & Abies sibirica & $\begin{array}{l}56.173583 \mathrm{~N} \\
92.179874 \mathrm{E}\end{array}$ & 2016 & $(2)$ & OK324334 \\
\hline & Ty2-16 & Basidiospores & Alnus Mill. & $\begin{array}{l}52.767116 \mathrm{~N} \\
95.641957 \mathrm{E}\end{array}$ & 2016 & $(2)$ & OK324332 \\
\hline
\end{tabular}

$6{ }^{\circ} \mathrm{C}$ at the Collection of Pure Cultures, Lab- slants into test tubes. oratory of Forest Cultures, Mycology and Phytopathology, V.N. Sukachev Institute of Forest, FRC KSC, Siberian Branch, Russian Academy of Sciences (Krasnoyarsk, Russia).

\section{Isolation from wood}

Wood with symptoms of necrosis was used for isolation. The wood surface was briefly sterilized in the flame of an alcohol lamp, then an indent was made by a sterile scalpel at the boundary of healthy and necrotic tissue, and thin fragments of several centimetres long were excised. Wood samples were placed into sterile Petri dishes at a distance one from another, impressing sharp edges into MEA+T by sterile tweezers. The dishes were incubated at $24^{\circ} \mathrm{C}$ without light and were regularly checked for contamination. Fast growing colonies of microscopic fungi were discarded together with agar medium by a sterile scalpel; slow growing colonies of Armillaria were transferred onto MEA
Isolation from fruit bodies (basidiomes) Fruit bodies were cleared of plant residues and soil. The surface of a fruit body was wiped with $96 \%$ ethanol and dried on filter paper. Then basidiomes were cut by a sterile scalpel; inner sterile fragments were excised and transferred into Petri dishes with MEA+T. The inoculations were incubated at $24{ }^{\circ} \mathrm{C}$ without light. The young mycelium emerging on pieces of fruit bodies was transferred onto MEA slants into test tubes.

\section{Isolation of fruit-body basidiospores}

Fruit bodies were cleared of plant residues and soil and placed for $24-48 \mathrm{~h}$ on sterile parchment paper by the spore-bearing layer to produce a spore print. The spore print was distributed along the surface of $1 \% \mathrm{ME}$ and incubated for $1-3$ days at $24{ }^{\circ} \mathrm{C}$. Germinated single spores were isolated using the method of Korhonen \& Hintikka (1980).

\section{Isolation from rhizomorphs}

The surface of a rhizomorph was sterilized in a $5 \%$ solution of calcium hypochlorite for $1 \mathrm{~min}$, successively washed in flowing tap water and sterile water, then quickly dried between sheets of sterile filter paper. Rhizomorphs were cut into fragments of about $1 \mathrm{~cm}$ long, which were immersed with one end into the depth of $2 \%$ MEA. Petri dishes were incubated at $24^{\circ} \mathrm{C}$ in the dark and were regularly checked for contamination. The emerging Armillaria mycelium (a tightly packed bunch of hyphae at the free end of the rhizomorph) was seeded onto fresh MEA into a Petri dish and then on MEA slants into test tubes.

\section{Colony morphology and}

microstructures

The morphological traits were studied during the cultivation of strains on MEA and Norkrans medium (Bukhalo 1988) at 24 ${ }^{\circ} \mathrm{C}$ for 28 days without illumination. Assessment was made of the occurrence, colour and structure of aerial mycelium; the occur- 
Fig. 2 - Distribution strains of six Siberian and Crimean Armillaria species.

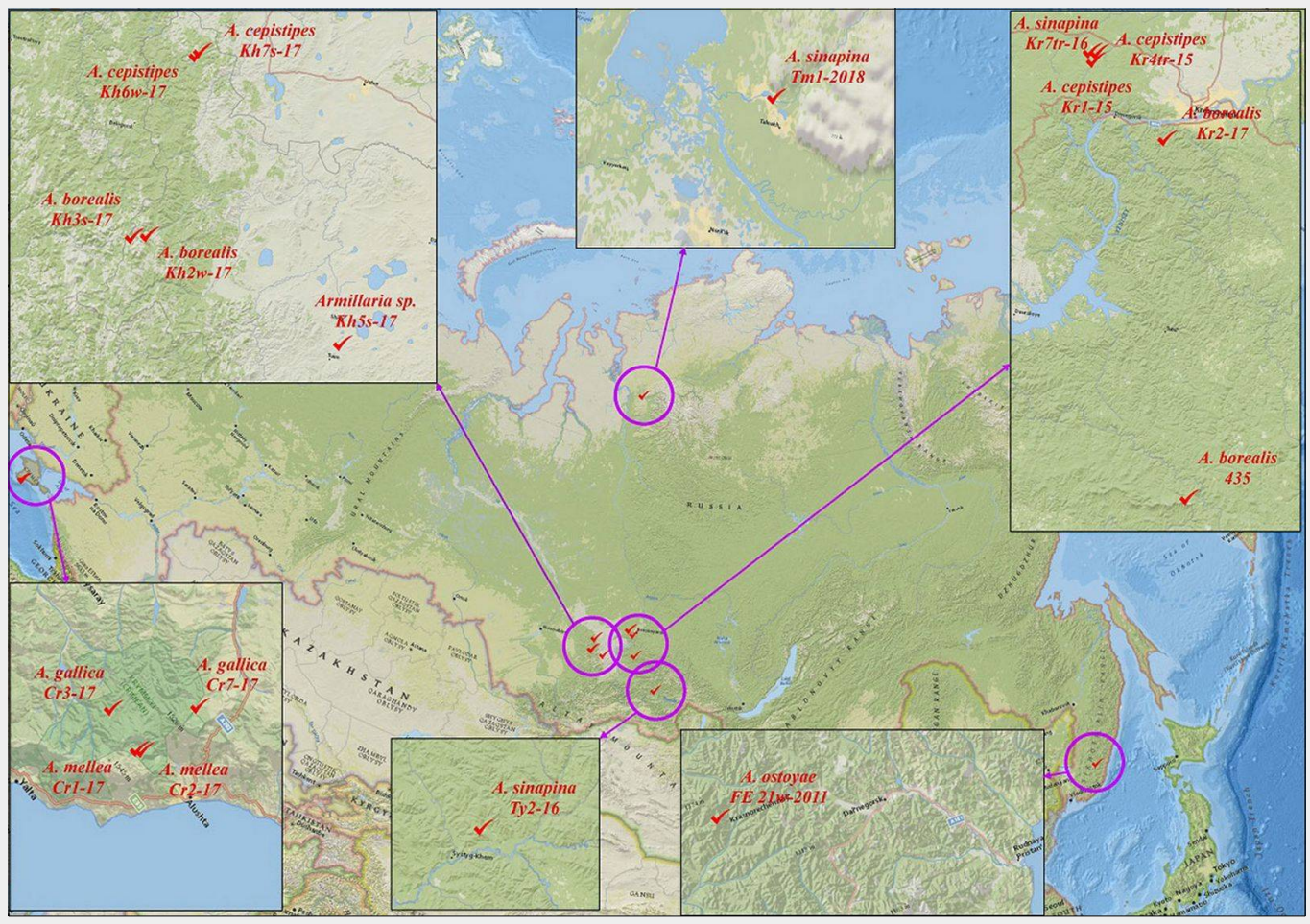

rence and pigmentation of rhizomorphs. Microstructures were investigated using an Eclipse $\mathrm{Ci}^{\circledast}$ light microscope (Nikon, Japan) and an $\mathrm{SU}_{3500^{\circledR}}$ scanning electron microscope (Hitachi, Japan). SEM specimens were prepared according to the standard protocol for fungi cultivated on a solid medium (Alves et al. 2012).

\section{DNA extraction, $P C R$ and sequencing}

Species identification of the investigated strains was supported by sequencing segments of ITS genetic marker using the facilities of the Shared Use Centre "Innovation Technologies of Plant Protection", All-Russian Institute of Plant Protection (St. Petersburg-Pushkin) and the Shared Use Centre "Genomics", Institute of Chemical Biology and Fundamental Medicine, Siberian Branch, Russian Academy of Sciences (Novosibirsk). DNA were isolated from the mycelium of pure cultures pregrown on $2 \%$ MEA for 21 days at $24^{\circ} \mathrm{C}$ without illumination. Use was made of a DNeasy ${ }^{\circledR}$ Plant Mini Kit (Qiagen Inc., Germantown, MD, USA) in accordance with the manufacturer's instructions; the DNA were stored at $-20{ }^{\circ} \mathrm{C}$. To determine the genetic affiliation of the studied fungal strains, the Sanger sequencing technology was used for the conserved regions of the internal transcribed spicers ITS1 and ITS2 (the first is located between the $18 \mathrm{~s}$ and $5.8 \mathrm{~S}$ gene regions, the second between the $5.8 \mathrm{~S}$ and $28 \mathrm{~S}$ rRNA regions). These sequences were amplified by PCR using the ITS1/ITS4 primer pair (White et al. 1990).

The $P C R$ reaction was run using a HotStarTaq ${ }^{\circledast}$ DNA polymerase kit (Qiagen, Great Britain). The mixtures for the PCR included a $10 \times \mathrm{PCR}$ buffer, $\mathrm{MgCl}_{2}$, dNTP, primers (100 $\mu \mathrm{M}$ each), $0.2 \mu$ l HotStarTaq
DNA polymerase, $2 \mu \mathrm{l}$ matrix DNA (20-100 ng) and $6.8 \mu \mathrm{l}$ MilliQ sterile water. The PCR was carried out using Mastercycler ${ }^{\oplus}$ pro Vapo-protect (Eppendorf, USA). The PCR amplification protocol was: $15 \mathrm{~min}$ initial denaturation at $95^{\circ} \mathrm{C}, 35$ cycles for $1 \mathrm{~min}$ denaturation at $95^{\circ} \mathrm{C}$, annealing of primers for $1 \mathrm{~min}$ at $50^{\circ} \mathrm{C}$ and extension for $1 \mathrm{~min}$ at $72{ }^{\circ} \mathrm{C}$, the final extension for 20 min at $72^{\circ} \mathrm{C}$; to complete the reaction, the subsequent holding at $4{ }^{\circ} \mathrm{C}$. The PCR products were visualized by electrophoresis in $1.5 \%$ agarose gel (Sigma, USA) stained by Roti $^{\circledR}$ GelStain (Carl Roth $\mathrm{GmbH}+$ Co. KG, Germany). PCR products of expected size were cleaned up using an innuPREP ${ }^{\circledR}$ gel extraction kit (AJ Innuscreen $\mathrm{GmbH}$, Germany).

\section{Strain cultivation conditions}

To study secondary metabolites, strains were cultivated in submerged culture in 750-ml Erlenmeyer flasks containing $100 \mathrm{ml}$ of a Norkrans synthetic medium (Bukhalo 1988) on a shaker (220 rpm) at $24^{\circ} \mathrm{C}$ for 14 days. The medium was inoculated with a suspension of a 14-day-old mycelium grown under stationary conditions at $24{ }^{\circ} \mathrm{C}$ in $3 \%$ MEA (Difco, USA)

\section{Isolation, identification and} quantitation of secondary metabolites

Secondary metabolites were extracted from the culture liquid filtrate by triple extraction with chloroform at $\mathrm{pH}$ 3.0. The extracts were analyzed by TLC on silica gel $\mathrm{F}_{254}$ plates (Merck, Germany) in chloroform : methanol : 25\% ammonia (90:10 : $0.1)$ and chloroform : acetone ( $93: 7)$ systems. The metabolites were found by absorption and fluorescence at 254 and 366 $\mathrm{nm}$ and after spraying the plates with a $10 \%$ solution of phosphomolybdic acid in etha- nol and $5 \%$ solution of $\mathrm{FeCl}_{3} \times 6 \mathrm{H}_{2} \mathrm{O}$ in methanol. The metabolites were isolated by preparative TLC on silica gel $F_{254}$ plates (Merck, Germany) in the solvent systems. Identification of the isolated metabolites was carried out by comparing the data of UV spectroscopy and mass spectroscopy with the literature sources (Dorfer et al. 2019a), databases (http://www.hmdb.ca/ metabolites, https://pubchem.ncbi.nlm.nih. gov/) and standard samples. Detailed information about the structures of the compounds was obtained at the analysis of MS/ MS spectra at a collision energy of $20-40 \%$.

The UV spectra of the compounds in methanol were recorded on a UV-160A spectrophotometer (Shimadzu, Japan). The mass spectra of the compounds were registered on an LCQ Advantage MAX quadrupole mass spectrometer (Thermo Finnigan, Germany), using a single-channel syringe pump for the direct injection of a specimen into the chamber for chemical ionization at atmospheric pressure. The total content of melleolides in extracts was determined semi-quantitatively using TLC and spectrophotometrically in methanol at $\lambda=303 \mathrm{~nm}$. The calculation was carried out using the molar extinction coefficient for melleolide C ( $\varepsilon=6300$ - Cardillo \& Nasini 1986).

\section{Phytotoxicity of melleolides in vitro}

Use was made of a mixture of melleolide $\mathrm{D}$ and melledonal $\mathrm{C}(1: 1)$ synthesized by strain A. mellea $\mathrm{Cr} 2-17$. For the required concentration of melleolides, a weight of the mixture was dissolved in a minimal volume of dimethylsufoxide (DMSO) and diluted with distilled water. 


\section{Formation of conifer seedlings}

Seeds of $P$. sylvestris and $L$. sibirica were pretreated with a $0.5 \%$ solution of $\mathrm{KMnO}_{4}$ for $3 \mathrm{~h}$, then washed twice with sterile water, placed on moistened filter paper in sterile Petri dishes. The seeds were incubated in a climate chamber (Jeio Tech, Republic of Korea) at a photoperiod of $12 \mathrm{~h}$, temperature of $24{ }^{\circ} \mathrm{C}$ and humidity of $70 \%$. For the experiment, use was made of 10day-old non-infected seedlings of close size.

\section{Phytotoxicity with respect to conifer seedlings}

A $0.5 \%$ solution of melleolides, into which the root systems of 10-day-old seedlings of $P$. sylvestris and $L$. sibirica were immersed, was poured into 5-ml Eppendorf tubes (1 plant per tube). Simultaneously, a control series of experiments was carried out with a solution containing DMSO and water at the same ratio as in the experiment but without melleolides. The test tubes were loaded into the holder; the total number for one experiment was 25 tubes. The climate conditions in the growth chamber: photoperiod, $12 \mathrm{~h}$; temperature, $24{ }^{\circ} \mathrm{C}$; humidity, 70\%; illuminance, $4500 \mathrm{~lx}$; duration of experiment for Pinus sylvestris, 14 days; for Larix sibirica, 21 days. The main estimated parameters: (i) viability (percentage of viable plants); (ii) foliage colour (3 points, green; 2 points, partial dechromation (transition from green to red-brown); 1 point, dechromation (loss of green pigmentation); (iii) foliage condition (3 points, healthy foliage, no withering; 2 points, weakened turgor, beginning of withering; 1 point, absence of turgor, withering); (iv) lengths of the aboveground part and of the main root, $\mathrm{mm}$.

\section{Production of Populus balsamifera L. calluses}

The callus culture was produced on primary explants of $P$. balsamifera. The cut upper parts of shoots (the explants) of about $3 \mathrm{~cm}$ in length were disinfected by immersion into $0.05 \% \mathrm{HgCl}_{2}$ for $5 \mathrm{~min}$ and then into $0.5 \% \mathrm{NaOCl}$ for $5 \mathrm{~min}$ (0.01\% Tween 80 was added to the disinfecting solutions). After the disinfection, the explants were washed three times with sterile distilled water. Further, the outer layer of cells on explant cuts was removed by a sterile scalpel, the explants were cut into smaller segments of about $1 \mathrm{~cm}$ long, dissected along the segment's length and placed by the cut side onto a Murashige-Skoog (MS) nutrient medium with sucrose and agar. The nutrient medium was additionally supplemented with thiamine $\left(0.45 \mathrm{mg} \mathrm{l}^{-1}\right)$, nicotinic acid (2.5 $\left.\mathrm{mg} \mathrm{l}^{-1}\right)$ and myo-inositol (100 $\left.\mathrm{mg} \mathrm{l}^{-1}\right)$. As growth regulators, we used indole butyric acid (IBA, $0.25 \mathrm{mg} \mathrm{l}^{-1}$ ), indole acetic acid (IAA, $0.85 \mathrm{mg} \mathrm{l}^{-1}$ ), a-naphthylacetic acid (NAA, 1.5 $\mathrm{mg} \mathrm{l}^{-1}$ ), kinetin (1.5 mg $\left.\mathrm{I}^{-1}\right)$, 2.4-dichlorophenoxyacetic acid (2,4-D, 2 $\mathrm{mg} \mathrm{l}^{-1}$ ), 6-benzylaminopurine (BAP, $5.5 \mathrm{mg}$ $\left.\mathrm{I}^{-1}\right)$. The explants were placed into sterile glass tubes and cultivated in a climate chamber: photoperiod, $24 \mathrm{~h}$; temperature, $24{ }^{\circ} \mathrm{C}$; illuminance, $4500 \mathrm{Ix}$; humidity, $70 \%$; duration, 25-30 days. The produced callus tissue was used as a test object to study the phytotoxicity of melleolides.

\section{Phytotoxicity with respect to $P$. balsamifera calluses}

The callus tissue divided into fragments was placed into sterile Petri dishes $(60 \times 20$ $\mathrm{mm}$ ) onto filter paper impregnated with a $2.5-\mathrm{ml}$ semi-liquid MS nutrient medium. Amounts of a $0.05-\mathrm{ml}$ melleolide solution at concentrations of $0.125 \%, 0.25 \%$ and $0.5 \%$ were applied onto callus tissue fragments. The total number of callus fragments for one experiment was 10; their masses varied from 0.021 up to $0.040 \mathrm{mg}$. Simultaneously, the control series of the experiment was carried out with a solution containing DMSO and water at similar ratios but without melleolides. The climate mode conditions in the growth chamber are described above; the duration of the experiment was 9 days. The phytotoxic action of melleolides on the callus culture was assessed with respect to four parameters (Kalinin et al. 1980, Butenko 1999, Tiidema \& Truve 2004, Tsyrenov 2003, Endress 1994): (i) raw biomass buildup with respect to the initial weight $(B, g)$; (ii) callus tissue buildup with account for time $\left(B_{t}\right.$, days $\left.^{-1}\right)$; (iii) specific growth rate $\left(\mu\right.$, days $\left.{ }^{-1}\right)$; (iv) rawbiomass growth rate index $(I)$.

$B$, the raw biomass buildup with respect to the initial weight (g) was calculated as follows (eqn. 1):

$$
B=\frac{W_{t}-W_{0}}{W_{0}}
$$

while $B_{t}$, the callus tissue buildup with account for time (days ${ }^{-1}$ ) was estimated as (eqn. 2):

$$
B_{t}=\frac{W_{t}-W_{0}}{W_{0}} \cdot \frac{1}{t}
$$

and $\mu$, the specific growth rate (days ${ }^{-1}$ ) as (eqn. 3):

$$
\mu=\frac{\ln W_{t}-\ln W_{0}}{t}
$$

and finally $I$, the raw-biomass growth rate index, as (eqn. 4):

$$
I=\frac{W_{t}}{W_{0}}
$$

where $t$ is time, $W_{0}$ is the initial weight of tissue, and $W_{t}$ is the final weight of tissue.

\section{Statistical analysis}

The statistical treatment of phytotoxicity was carried out using the Microsoft Office Excel $^{\circledR} 2013$ software package. We calculated the mean, standard errors of the experiment for each sample, as well as the Student's t-test between control and experiment. The results were considered to be statistically significant at $p<0.05$.

Cluster analysis with the unweighted pair group method with arithmetic mean (UP-
GMA) was performed to compare the differences of strains in the profiles of melleolides based on a matrix based on the presence or absence of metabolites (their trace amounts were not taken into account).

\section{Results and discussion}

\section{Morphology}

Most investigated Armillaria strains formed on $2 \%$ MEA slow growing low leathery velvety colonies of white creamy brown colour. On days 7-10 in the depth of the agar medium we noted the formation of well developed, strongly branching white rhizomorphs, which darkened as the culture aged (days 21 to 28). On a Norkrans medium, all cultures formed low colonies; aerial mycelium was scarce, stained or nonpigmented; rhizomorphs were not numerous, short, sharp, weakly branching, darkcoloured.

No significant distinctions of microscopic structures in the investigated strains were revealed. The fungi formed a well-developed septate mycelium; generative hyphae were of light brown colour, semi-transparent; the hyphae were observed to branch at an acute angle, more rarely at a right angle; the width of the hyphae was 2.0-3.5 $\mu \mathrm{m}$; the anastomoses between hyphae were moderate; some hyphae had rough surfaces due to the formation of spherical structures. Skeletal hyphae formed during ageing of cultures on days 30-35; they were darker (from light- to dark-brown colour), without septa, 1.5-3.0 $\mu \mathrm{m}$ wide. In old parts of the colony, mass clusters of spherical thick-walled hollow cells 5-16 $\mu \mathrm{m}$ in diameter formed (Fig. 3).

Species identification was established by molecular genetic methods. A total of 17 isolates of Armillaria were analyzed; the phylogenetic tree are based on the combined multiple alignment of nucleotides of ITS markers (Fig. 4). The investigated isolates were grouped into six clades corresponding to the known species with a high level of statistical support: four isolates, into the $A$. borealis clade; five, into the $A$. cepistipes clade; two, into the $A$. gallica clade; three, into the A. sinapina clade; two, into the A. mellea clade; one, into the A. ostoyae clade. Thus, in Siberia (South Krasnoyarsk Krai, Republic of Tyva, Republic of Khakassia, Taimyr Peninsula), from coniferous and broadleaved plants we isolated the species of $A$. borealis, $A$. cepistipes and A. sinapina; in Russian Far East (SikhoteAlin), the species A. ostoyae; in Crimea (Krymsky National Park, Chatyr-Dag Mountain Lower Plateau), the species of $A$. gallica and A. mellea (Tab. 1, Fig. 2). The identified species of Armillaria are widespread in forest stands of the North Hemisphere (Baumgartner et al. 2011). Their distribution areas are determined, first and foremost, by climatic conditions of the area and the occurrence of a host plant. The data of Armillaria spp. isolated in the Russian Federation have not been widely discussed in the 

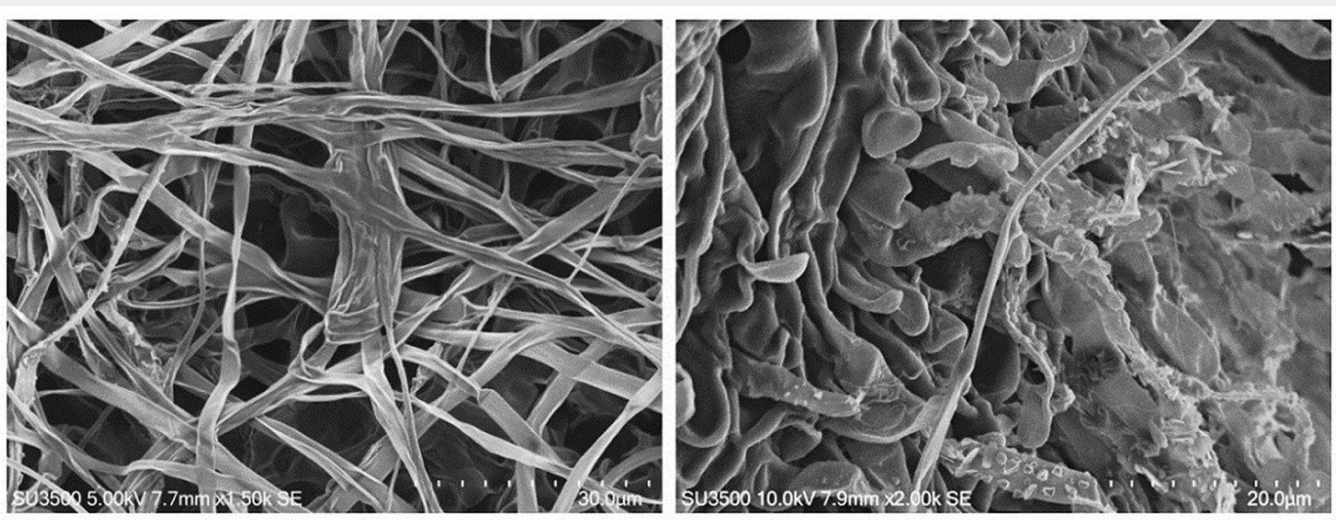

Fig. 3 - Scanning electron microscopy of Armillaria strains, ×1400-2000. Upper left to lower right: $A$. borealis vegetative mycelium; A. cepistipes rough mycelium; A. sinapina mycelium and thick-walled spherical cells; thick-walled spherical and ellipsoid cells in the old part of $A$. mellea colony.
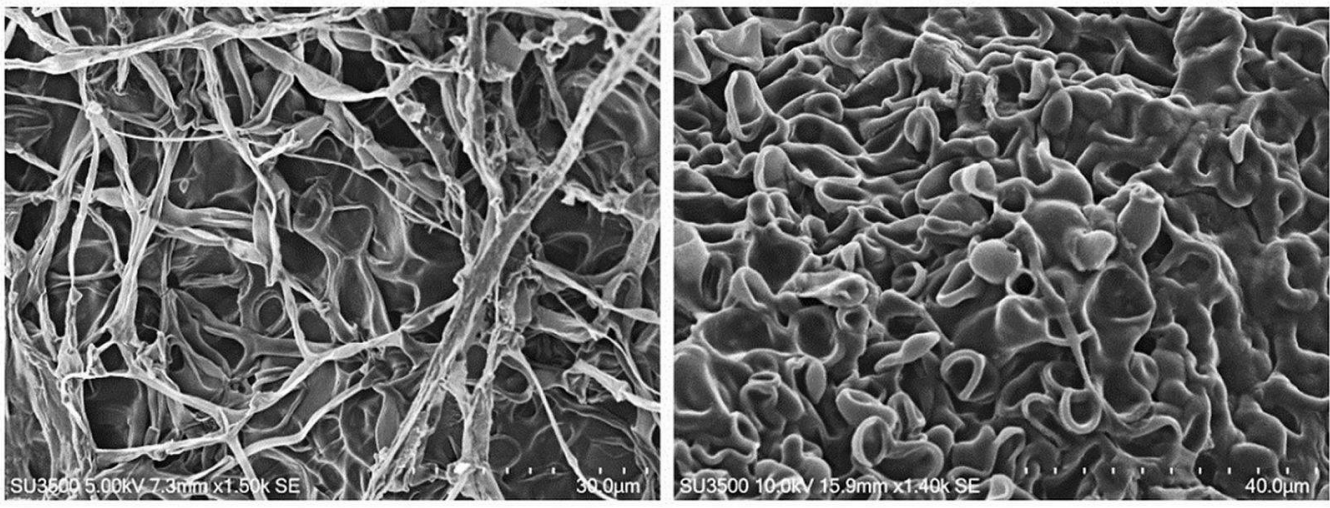

foreign literature, probably, due to the ab- ited by $58^{\circ} \mathrm{N}$ and $52^{\circ} \mathrm{S}$ (Pavlov et al. 2017). sence of the genetic verification of isolates.

\section{An earlier work has established the abso- Secondary metabolites}

lute dominance of the species A. borealis in Analysis of extracts from the culture liqKrasnoyarsk Krai forests within an area lim- uid of the investigated strains showed the

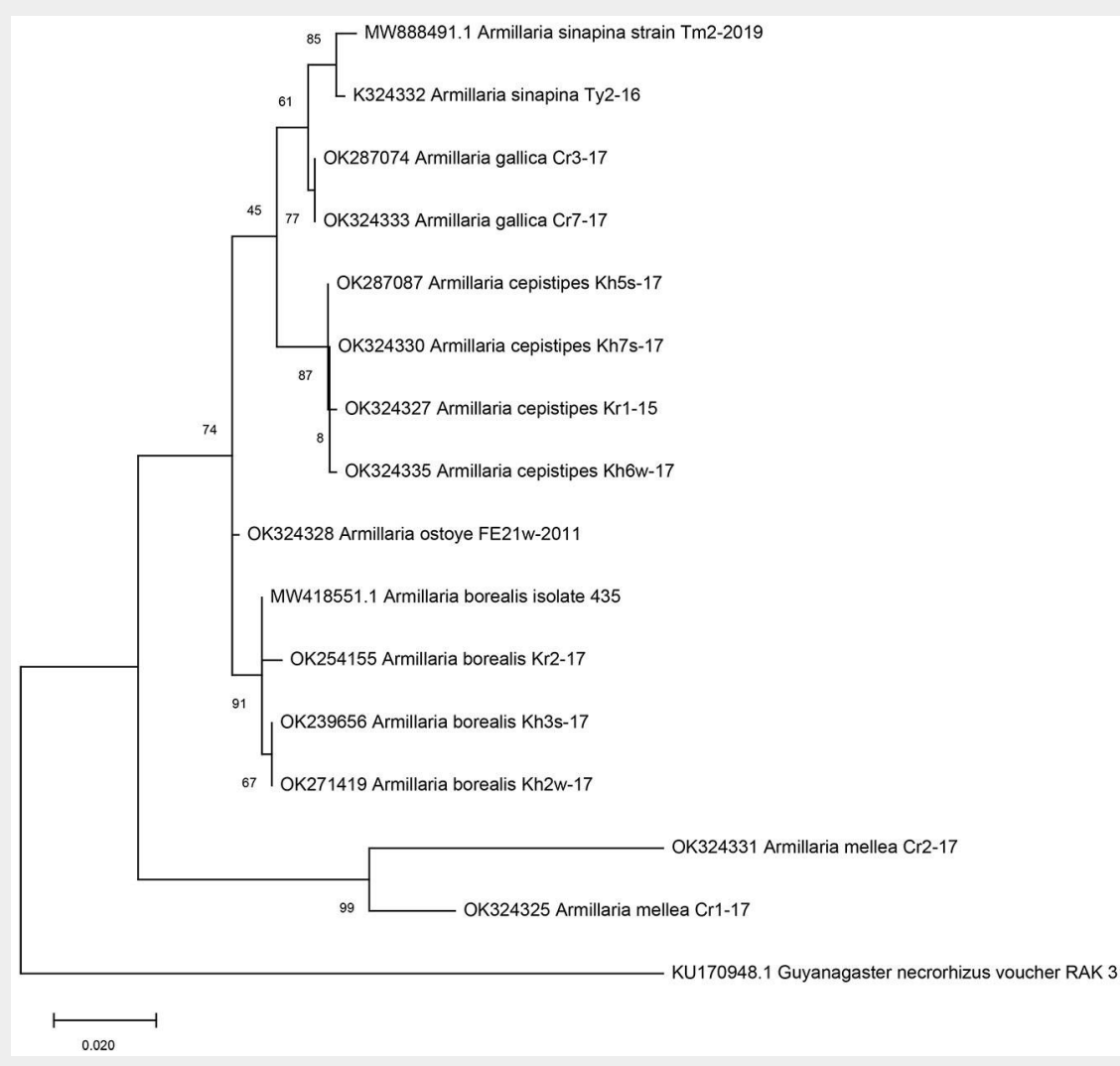

Fig. 4 - Phylogenetic tree of Armillaria spp. based on comparative analyses of the ITS1ITS2 region. presence in samples of secondary metabolites that absorbed UV light, reacted to a $5 \%$ solution of $\mathrm{FeCl}_{3}$ in methanol and a $10 \%$ solution of phosphomolybdic acid in ethanol, but differed by their chromatographic mobility. The UV spectra of the extracts and isolated metabolites contained the maximum values of the absorption bands at 216, 263 and 302-304 nm. This was indicative of a common structural core in molecules of the compounds in the form of a hydroxylated aromatic ring, which occurs in melleolides.

Using mass spectrometry, in all investigated strains of Armillaria spp. we found metabolite 1 with a molecular ion $[\mathrm{M}-\mathrm{H}]$ ] at $\mathrm{m} / \mathrm{z} 479$, which contained a chlorine atom with a $3: 1$ isotope distribution of intensities (Tab. S1 in Supplementary material). The MS/MS spectrum was observed to have a fragment ion at $\mathrm{m} / \mathrm{z} 215$, also containing a chlorine atom corresponding to fragment $\left[\mathrm{C}_{9} \mathrm{H}_{8} \mathrm{O}_{4} \mathrm{Cl}\right]$ formed during the rupture of the ester bond. The obtained characteristics of metabolite 1 corresponded to melledonal $\mathrm{C}$. All strains synthesized metabolite 2 with a molecular ion [M-H] at $\mathrm{m} / \mathrm{z} 481$, which also contained a chlorine atom and a fragment ion at $\mathrm{m} / \mathrm{z} 215$. Based on the literature data, metabolite 2 was identified as melleolide $D$. In 11 strains, metabolite 3 with a molecular ion $[\mathrm{M}-\mathrm{H}]$ at $\mathrm{m} /$ $z 447$ was found. Its MS/MS spectrum was observed to have a fragment ion at $\mathrm{m} / \mathrm{z} 181$ corresponding to the fragment $\left[\mathrm{C}_{9} \mathrm{H}_{9} \mathrm{O}_{4}\right]$, which pointed to melleolide $\mathrm{C}$. In 10 strains, metabolite 5 with a molecular ion $[\mathrm{M}-\mathrm{H}]$ at $\mathrm{m} / \mathrm{z} 431$ was found, which in the MS/MS spectrum formed a fragment at $\mathrm{m} / \mathrm{z} 181$ and was identified as melleolide $B$. Nine 
Tab. 2 - Metabolome of investigated Armillaria strains.

\begin{tabular}{|c|c|c|c|c|c|c|c|c|c|c|c|c|c|c|c|c|c|}
\hline \multirow[b]{2}{*}{ Metabolite } & \multicolumn{3}{|c|}{$\begin{array}{l}\text { A. } \\
\text { borealis }\end{array}$} & \multirow[b]{2}{*}{ 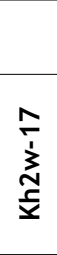 } & \multirow{2}{*}{ 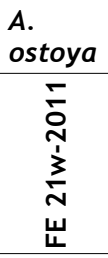 } & \multicolumn{3}{|c|}{$\begin{array}{l}\text { A. } \\
\text { sinapina }\end{array}$} & \multicolumn{2}{|c|}{$\begin{array}{l}\text { A. } \\
\text { mellea }\end{array}$} & \multicolumn{2}{|c|}{$\begin{array}{l}\text { A. } \\
\text { gallica }\end{array}$} & \multicolumn{5}{|c|}{$\begin{array}{l}\text { A. } \\
\text { cepistipes }\end{array}$} \\
\hline & $\stackrel{\llcorner}{\sim}$ & $\begin{array}{l}\hat{i} \\
\stackrel{\tilde{m}}{\tilde{y}} \\
\frac{\hat{x}}{2}\end{array}$ & 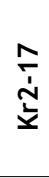 & & & 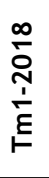 & & $\underset{⿱ 亠}{\stackrel{1}{Z}}$ & $\frac{\pi}{\frac{1}{5}}$ & 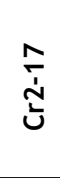 & $\frac{\hat{s}}{\frac{1}{2}}$ & $\frac{\hat{p}}{\stackrel{\mathfrak{m}}{u}}$ & 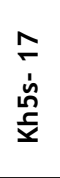 & $\frac{\substack{\infty \\
\frac{1}{\xi}}}{\models}$ & $\frac{\hat{\Sigma}}{\frac{\hat{n}}{\hat{n}}}$ & $\frac{\frac{n}{1}}{\frac{1}{x}}$ & $\frac{n}{\frac{n}{5}}$ \\
\hline Melleolide B & + & + & + & + & + & + & + & + & - & - & - & - & + & - & - & - & - \\
\hline Melledonal B & - & + & + & + & - & - & - & + & + & - & + & + & + & + & + & - & - \\
\hline Melleolide C & + & - & + & - & + & + & + & - & - & - & - & + & + & + & + & + & + \\
\hline Melleolide D & + & + & + & + & + & + & + & + & + & + & + & + & + & + & + & + & + \\
\hline Melledonal C & + & + & + & + & + & + & + & + & + & + & + & + & + & + & + & + & + \\
\hline 5'-0-methoxymelledonal & + & - & + & - & + & + & + & + & + & - & - & - & + & - & - & - & + \\
\hline Melleolide H & - & - & - & - & - & - & + & + & - & - & - & - & - & - & - & - & - \\
\hline 13-hydroxy-5'-0-methylmelledonal & - & - & - & - & - & + & - & - & - & - & - & - & - & - & - & - & - \\
\hline Armillarinin & - & - & - & - & + & - & - & - & - & + & + & - & - & - & - & - & + \\
\hline Arnamiol & - & + & - & - & - & - & + & - & - & - & - & - & - & + & - & - & - \\
\hline Melledonal & + & + & - & - & + & - & - & - & - & - & + & + & - & - & - & - & - \\
\hline Melledonol & + & + & + & - & - & - & - & - & - & - & - & + & + & - & - & - & - \\
\hline Melleolide L & - & - & - & - & - & - & - & - & - & - & + & + & + & - & - & - & - \\
\hline Melleolide M & - & - & - & - & - & - & - & - & - & - & + & + & + & - & + & - & - \\
\hline 10-hydroxy-5'-methoxy-6'-chloroarmillan & + & - & - & - & - & - & - & - & + & - & - & - & - & - & + & - & - \\
\hline Production of melleolides $\left(\mathrm{mg} \mathrm{l}^{-1}\right)$ & 188 & 20 & 15 & 6 & 4 & 6 & 24 & 16 & 2 & 239 & 22 & 196 & 82 & 44 & 53 & 29 & 60 \\
\hline
\end{tabular}

strains synthesized metabolite 4 with a molecular ion $[\mathrm{M}-\mathrm{H}]$ ] at $\mathrm{m} / \mathrm{z} 445$, which also yielded a fragment at $\mathrm{m} / \mathrm{z} 181$. Based on the obtained data, this metabolite was identified as $5^{\prime}$-methoxymelledonal. Nine strains synthesized metabolite 6 with a molecular ion $[\mathrm{M}-\mathrm{H}]$ ] at $\mathrm{m} / \mathrm{z} 465$, which yielded a fragment at $\mathrm{m} / \mathrm{z} 215$. This metabolite was identified as melledonal B. In extracts of 4 strains, we identified metabolite 7 with a molecular ion [M-H] at $\mathrm{m} / \mathrm{z} 431$, and in four other strains, metabolite 8 with a molecular ion $[\mathrm{M}-\mathrm{H}]$ ] at $\mathrm{m} / \mathrm{z} 433$, whose MS/MS spectra had a fragment at $m / z 165$, pointing to the occurrence of 2,4-dihydroxy-6methylbenzoate in the structure. The obtained data corresponded to melledonal and melledonol, respectively. Four strains were found to have metabolite 9 with a molecular ion [M-H] at $\mathrm{m} / \mathrm{z} 463$; the MS/MS spectrum of this compound was observed to have a fragment at $\mathrm{m} / \mathrm{z} 215$. The obtained data are characteristic of armillarinin. In 3 strains, metabolite 10 with a molecular ion [M-H] at $\mathrm{m} / \mathrm{z} 449$ was present; its MS/MS spectrum contained a fragment at $\mathrm{m} / \mathrm{z} 215$, which is characteristic of arnamiol. In 3 strains, we observed metabolites 11 and 12 with molecular ions [M-H] at $\mathrm{m} / \mathrm{z} 449$, and in yet other three strains, an ion $[\mathrm{M}-\mathrm{H}]$ ] at $\mathrm{m} / \mathrm{z}$ 451. Their MS/MS spectra were observed to have a fragment at $\mathrm{m} / \mathrm{z} 201$, which was indicative of the presence of 3-chloro-4,6-dihydroxy-2-methylbenzoate. These metabolites were identified as melleolides $L$ and $M$, respectively. Three strains synthesized metabolite 13 having a molecular ion [M-H] at $\mathrm{m} / \mathrm{z} 483$, the MS/MS spectrum of which had a frag- ment at $\mathrm{m} / \mathrm{z} 215$. These data are characteristic of 10 -hydroxy-5'-methoxy-6'-chloroarmillan. The spectra of 2 strains showed metabolite 14 with a molecular ion [M-H] at m/ $z$ 429; it formed a fragment at $\mathrm{m} / \mathrm{z} 181$, which was indicative of melleolide $\mathrm{H}$. Two strains were found to synthesize metabolite 15 having an ion [M-H] at $\mathrm{m} / \mathrm{z} 461$, which was identified as 13-hydroxy-5'-Omethylmelledonal.

Thus, we identified 15 various tricyclic sesquiterpene aryl esters (melleolides) in the investigated Armillaria fungi. All strains belonged to different species and contained melleolide $D$ and melledonal $C$ in their spectra (Tab. 2). These compounds differ by the presence of the alcohol or aldehyde groups at $\mathrm{C}-1$ of the protoilludane ring, respectively, have a chlorine atom at C-6' and a methyl group at $\mathrm{C}-5^{\prime}$ ' of the orsellinic ring. The compositions of other melleolides synthesized by the strains varied significantly. We can note the presence of certain melleolides in strains of one species. Thus, besides melleolide $D$ and melledonal $C$, all investigated $A$. borealis strains (South Siberia; A. sibirica, B. pendula) formed melleolide $B$. Three $A$. borealis strains synthesized its chlorine derivative melledonal $B$ (these compounds predominated in the metabolome of these fungi) and melledonol. In two of four investigated $A$. borealis strains we identified melleolide $C, 5^{\prime}-\mathrm{O}$ methoxymelledonal and melledonal. In the profile of A. cepistipes metabolome (South Siberia; B. pendula and A. sibirica), melleolide D predominated; melledonal $C$ and less widespread melleolide $C$ were also identified in all investigated strains. All A. sinapina strains, apart from melleolide $D$ and melledonal C, formed 5'-O-methylmelledonal and melleolide $\mathrm{B}$. Melleliod $\mathrm{H}$ and 13-hydroxy-5'-O-methylmelledonal were found only in strains of this species. In two investigated $A$. gallica strains were found melledonal B, melleolide C, melledonal, and rare melleolides $L$ and $M$. The rest of the melleolides were found in single strains of different species.

The cluster analysis of strains according to the profiles of melleolides did not reveal the relationship between the biosynthesis of these compounds and the strains of the Armillaria species. (Fig. S2 in Supplementary material). The analysis showed that, according to the level above $60 \%$ similarity, the strains can be divided into four clusters. It can be noted the $80 \%$ similarity of $A$. gallica $\mathrm{Cr} 7-17$ and $\mathrm{Cr}_{3}-17$ (Crimea; $\mathrm{C}$. betulus and Q. petraea) were included in cluster $A$. A high level of similarity was observed in $A$. borealis strains 435 and $\mathrm{Kr2}-17$ (basidiospores and wood A. sibirica, respectively), and in strains A. borealis Kh3s-17 and Kh2W17 (basidiospores and wood B. pendula). Apparently, the biosynthesis of melleolides has strain differences associated with the geographic effect associated with different climates and the host plant. The number of individuals per species in this study does not allow us to conclude about the possible reasons for the appearance of various metabolites and to associate it with the ability of each species of Armillaria species to infect living trees. In addition, a geographical effect associated with different climates could affect these productions, independently of the species effect. 


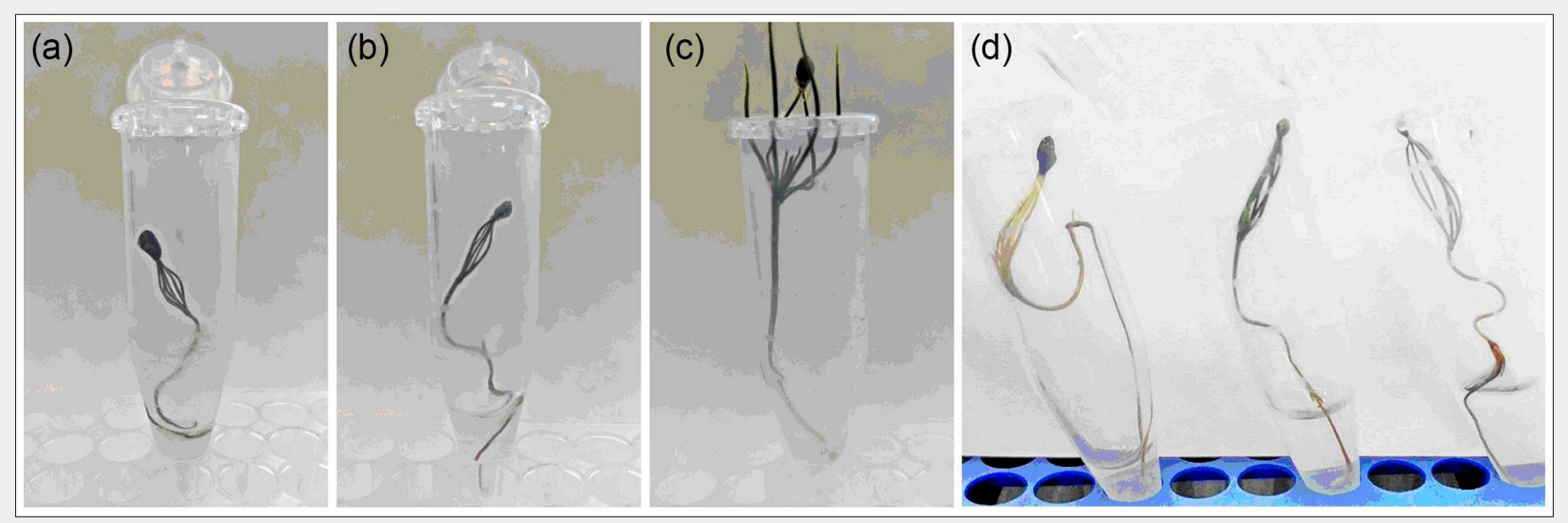

Fig. 5 - Pinus sylvestris (a, b, c) and Larix sibirica (d) seedlings on day 7 of the experiment under the action of the melleolide mixture at a concentration of $0.5 \%$ (controls: in a and d, right tube).

In the submerged culture on a Norkrans medium, production of melleolides by Armillaria strains differed significantly: their maximum accumulation varied from 2 up to $239 \mathrm{mg} \mathrm{l}^{-1}$ (Tab. 2). The most active producers were strains $A$. borealis 435, A. gallica $\mathrm{Cr}_{3}-17$ and $\mathrm{A}$. mellea $\mathrm{Cr} 2-17$, which accumulated melleolides at an amount of 188, 196 and $239 \mathrm{mg} \mathrm{l}^{-1}$, respectively.

\section{Phytotoxicity of melleolides}

The phytotoxic action of melleolides has been studied earlier on the callus culture Picea abies and salad seedlings (Peipp \& Sonnenbichler 1992, Kobori et al. 2015). At present, the phytotoxicity of melleolides is associated with the occurrence of methyl ester at $0-5^{\prime}$ of the orsellinic ring of the molecules (Dorfer et al. 2019a). Ten melleolides identified in the investigated fungi have the same structure and, therefore, are capable of a phytotoxic action on plants. Given that, the synthesis of the two compounds - melleolide D and melledonal $C$ - was observed in all the investigated Armillaria strains irrespective of their species membership.

The mixture of melleolide $D$ and melledonal $C(1: 1)$ was obtained from the culture filtrate of $\mathrm{A}$. mellea $\mathrm{Cr} 2-17$, which is characterized by the maximum production of melleolides in vitro as compared with the other investigated Armillaria cultures. Studies of three melleolide concentrations (0.125\%, $0.25 \%$ or $0.5 \%$ ) showed melleolides at a concentration of $0.5 \%$ to significantly inhibit the growth parameters of the P. balsamifera callus culture for nine days (Tab. S2 in Supplementary material). We noted a decrease in the build up of raw biomass with respect to the initial weight 2.3 and 2.1 times by days 5 and 9, respectively; in the callus tissue buildup with account for time, 2.7 and 2.3 times, respectively; specific growth rate, 2 and 1.5 times; raw-biomass growth rate index, 1.2 times.

Studies of the effect of the mixture of melleolide $D$ and melledonal $C$ at a concentration of $0.5 \%$ on 10 -day-old coniferous seedlings showed a higher sensitivity of $P$. sylvestris as compared with L. sibirica. Already on day 5 of the experiment, the viability of $P$. sylvestris seedlings decreased 1.9 times; and on day 14, 28 times as compared with the control (Fig. 5, Tab. S3 in Supplementary material). Starting from day 7 , active dechromation of needles and loss of turgor were observed. On day 14, the length of the aboveground part of the plant was 2.1 times smaller, and the length of the main root, 2.8 times smaller as compared with the control.

The effect of the melleolide mixture on $L$. sibirica seedlings was less pronounced: on day 14 of the experiment the viability of the plants decreased 1.6-fold; on day 21, 2.1fold as compared with the control (Fig. 5, Tab. S4 in Supplementary material ). The viability of L. sibirica seedlings on day 21 (47\%) was comparable with the parameters for P. sylvestris seedlings on day 5 (50\%). By the experiment completion time, the condition of the foliage was 2 points (a partial loss of turgor and dechromation of foliage); the length of the aboveground part and that of the main root was 1.3- and 1.2fold less as compared with the control, respectively.

\section{Conclusions}

In this study 15 various tricyclic sesquiterpene aryl esters (melleolides) were identified in the metabolome profile of Armillaria strains of six Siberian and Crimean Armillaria species. Universal metabolites revealed in strains of all investigated species ( $A$. borealis, A. cepistipes, A. gallica, A. mellea, A. ostoyae, A. sinapina) are melleolide D and melledonal C. The compositions of other melleolides showed strain-specific differences. The most active producers of melleolides were strains $A$. borealis 435, $A$. gallica $\mathrm{Cr}_{3}-17$ and $\mathrm{A}$. mellea $\mathrm{Cr} 2-17$, which accumulated melleolides at an amount of 188, 196 and $239 \mathrm{mg} \mathrm{l}^{-1}$, respectively.

The phytotoxic action of a mixture of compounds (melleolide D and melledonal C) common for all investigated Armillaria strains on broadleaved and coniferous test trees was shown. At a concentration of
$0.5 \%$, the mixture obtained from the most productive strain A. mellea $\mathrm{Cr}_{2}-17$ inhibited the growth processes of the callus culture $P$. balsamifera and 10-day-old seedlings of coniferous plants (the maximum sensitivity was characteristic of $P$. sylvestris). We noted a 2.2-fold decrease on average in the raw biomass build up of the $P$. balsamifera callus as compared with the control; a decrease of the viability of $P$. sylvestris and $L$. sibirica seedlings (maximally 28 and 2.1 times, respectively, as compared with the control), inhibition of the growth of the stem and roots; dechromation of foliage; loss of turgor.

The occurrence of a wide range of tricyclic sesquiterpene aryl esters with various biological activities in the metabolome profile, the presence of two common compounds (melleolide D and melledonal C), having a phytotoxic action in vitro with respect to $P$. balsamifera calluses and $P$. sylvestris, $L$. sibirica seedlings, enables considering the synthesis of melleolides by Armillaria fungi as one of the possible pathogenicity mechanisms playing an important role in forest stand drying. Proceeding from the premise that under in vitro conditions the phytotoxic effect was exhibited at a sufficiently high concentration of melleolides (0.5\%), this pathogenicity mechanism is probably realized efficiently only in strains that possess melleolide overproduction under natural conditions.

\section{References}

Alves E, Lucas GC, Pozza EA, Alves De M C (2012). Scanning electron microscopy for fungal sample examination. In: "Laboratory Protocols in Fungal Biology: Current Methods in Fungal Biology" (Gupta VK, Tuohy MG, Ayyachamy M, Turner KM, O’Donovan A eds). Springer New York, New York, USA, pp. 133-150. - doi: 10.1007/ 978-1-4614-2356-0_8

Baumgartner K, Coetzee MP, Hoffmeister D (2011). Secrets of the subterranean pathosystem of Armillaria. Molecular Plant Pathology 12 (6): 515-534. - doi: 10.1111/J.1364-3703.2010.0069 3. $\tilde{N}$

Bohnert D, Nutzmann H-W, Schroeckh V, Horn F, 
Dahse H-M, Brakhage AA, Hoffmeister D (2014). Cytotoxic and antifungal activities of melleolide antibiotics follow dissimilar structure-activity relationships. Phytochemistry 105: 101-108. doi: 10.1016/j.phytochem.2014.05.009

Bukhalo AS (1988). Higher edible basidiomycetes in pure culture. Naukova Dumka, Kiev, Ukraine, pp. 144. [in Russian]

Butenko RG (1999). Biology of higher plant cells in vitro and biotechnologies on their basis (study guide). FBK-Press, Moscow, Russia, pp. 160. [in Russian]

Cardillo R, Nasini G (1986). Structures of melleolides B-D, three antibacterial sesquiterpenoids from Armillaria mellea. Phytochemistry 25 (2) 471-474. - doi: 10.1016/S0031-9422(00)85503-X

Chen YJ, Chen CC, Huang HL (2016). Induction of apoptosis by Armillaria mellea constituent armillarikin in human hepatocellular carcinoma. OncoTargets and Therapy 9: 4773-4783. - doi 10.2147/OTT.S103940

Coetzee MPA, Wingfield BD, Wingfield MJ (2018). Armillaria root-rot pathogens: species boundaries and global distribution. Pathogens 7 (4): 83. - doi: 10.3390/pathogens7040083

Dorfer M, Gressler M, Hoffmeister D (2019a). Diversity and bioactivity of Armillaria sesquiterpene aryl ester natural products. Mycological Progress 18: 1027-1037. - doi: 10.1007/s11557-01901508-z

Dorfer M, Heine D, Konig S, Gore S, Werz O, Hertweck C, Gressler M, Hoffmeister D (2019b). Melleolides impact fungal translation via elongation factor 2. Organic and Biomolecular Chemistry 17: 4906-4916. - doi: 10.1039/C9OBoo $562 \mathrm{E}$

Endress R (1994). Plant cell biotechnology. Springer-Verlag, Berlin, Heidelberg, Germany, pp. 353. - doi: 10.1007/978-3-662-02996-1

Guillaumin JJ, Mohammed C, Courtecuisse N AR, Gregory SC, Holdenrieder O, Intini M, Lung B, Marxmüller H, Morrison D, Rishbeth J, Termorshuizen AJ, Tirro A, Van Dam B (1993). Geographical distribution and ecology of the Armillaria species in western Europe. Forest Pathology 23 (6-7): 321-341. - doi: 10.1111/j.1439-0329.19 93.tboo814.x

Kalinin FL, Sarnatskaya VV, Polishchuk VE (1980). Tissue culture methods in plant physiology and biochemistry. Naukova Dumka, Kiev, Ukraine, pp. 488. [in Russian]

Kobori H, Sekiya A, Suzuki T, Choi J, Hirai H, Kawagishi $H$ (2015). Bioactive sesquiterpene aryl esters from the culture broth of Armillaria sp. Journal of Natural Products 78 (1): 163-167. doi: $10.1021 / n p 500322 t$

Korhonen K, Hintikka V (1980). Simple isolation and inoculation methods for fungal cultures. Karstenia 20: 19-22. - doi: 10.29203/ka.1980.192

Maloy OC (1974). Benomyl-malt agar for the purification of cultures of wood decay fungi. Plant Disease Reporter 58: 902-904.

Marçais B, Bréda N (2006). Role of an opportunistic pathogen in the decline of stressed oak trees. Journal of Ecology 94: 1214-1223. - doi: 10.1111/j.1365-2745.2006.01173.x

Misiek M, Hoffmeister D (2012). Sesquiterpene aryl ester natural products in North American Armillaria species. Mycological Progress 11 (1): 7-15. - doi: 10.1007/s11557-010-0720-3

Momose I, Sekizava R, Hosokawa N, linuma H, Matsui S, Nakamura H, Naganawa H, Hamada M, Takeuchi T (2000). Melleolides K, L and M, new melleolides from Armillariella mellea. Journal of Antibiotics 53 (2): 137-143. - doi: 10.7164/ antibiotics.53.137

Morrison DJ, Pellow KW (2002). Variation in virulence among isolates of Armillaria ostoyae. Forest Pathology 32: 99-107. - doi: 10.1046/j.1439-03 29.2002.00275.x

Pavlov IN, Litovka Y, Litvinova EA, Timofeev AA, Pashenova NV, Safronova IE, Kulakov SS, Mulyava VV, Mulyava VE (2017). Armillaria borealis Marxm. and Korhonen: distribution, phytopathogenicity and morphological and cultural features. AgroEko-Info 29 (3): 18. [online] URL: http://agroecoinfo.narod.ru/journal/STATYI/201 7/3/st 307.doc

Peipp $\bar{H}$, Sonnenbichler J (1992). Occurrence of antibiotic compounds in cultures of Armillaria ostoyae growing in the presence of an antagonistic fungus or host plant cells. Biological Chemistry Hoppe-Seyler 373 (2): 675-684. - doi: 10.1515/bchm3.1992.373.2.675

Prospero S, Holdenrieder O, Rigling D (2004). Comparison of the virulence of Armillaria cepistipes and Armillaria ostoyae on four Norway spruce provenances. Forest Pathology 34: 1-14. - doi: 10.1046/j.1437-4781.2003.00339.x Tiidema A, Truve E (2004). Efficient regeneration of fertile barley plants from callus cultures of several Nordic cultivars. Hereditas 140: 171-176. doi: 10.1111/j.1601-5223.2004.01757.x

Tsyrenov VZ (2003). Basics of biotechnology: cultivation of isolated plant cells and tissues (study guide). ESSTU, Ulan-Ude, Russia, pp. 58. [in Russian]

White TJ, Bruns T, Lee S, Taylor J (1990). Amplification and direct sequencing of fungal ribosomal RNA genes for phylogenetics. In: "PCR protocols: A guide to Methods and Applications", (Innis N, Gelfand D, Sninsky J, White T eds). Academic Press, New York, USA, pp. 315-322. doi: 10.1016/B978-0-12-372180-8.50042-1

Whitney RD, Myren DT, Britnell WE (1978). Comparison of malt agar with malt plus orthophenylphenol for isolating Armillaria mellea and other fungi from conifer roots. Canadian Journal of Forest Research 8: 348-351. - doi: 10.1139/ x78-052

Zhelifonova VP, Antipova TV, Litvinova EA, Baskunov BP, Litovka Y, Pavlov IN, Kozlovsky AG (2019). Biosynthesis of protoilludene sesquiterpene aryl esters by siberian strains of the genus Armillaria fungi. Applied Biochemistry and Microbiology 55 (3): 277-283. - doi: 10.1134/ So003683819030153

\section{Supplementary Material}

Tab. S1 - Mass spectrometric characteristics of metabolites isolated from the culture liquid of Armillaria fungi.

Tab. S2 - Effect of the melleolide mixture on the growth parameters of the Populus balsamifera callus culture.

Tab. S3 - Effect of the melleolide mixture on Pinus sylvestris growth processes.

Tab. S4 - Effect of the melleolide mixture on Larix sibirica growth processes.

Fig. S1 - Dendrogram of the similarity of Armillaria fungi strains in terms of biosynthesis of identified melleolides.

Link: Antipova_3840@supplo01.pdf 